\title{
Restoring the Public Trust in the Patient-Physician Relationship
}

\author{
Fleming RM ${ }^{1 *}$, Fleming $\mathrm{MR}^{1}$ and Chaudhuri $\mathrm{TK}^{2}$ \\ 1FHHI-OmnificImaging-Camelot, El Segundo, USA \\ 2Eastern Virginia Medical School, Norfolk, USA \\ *Corresponding author: Richard M Fleming, PhD, MD, JD, Los Angeles, CA, USA, Tel:
}

818-210-6930; Email: DrRichardMFleming@gmail.com

\section{Letter to Editor}

Volume 2 Issue 2

Received Date: August 13, 2019

Published Date: August 20, 2019

DOI: $10.23880 /$ ijnmrs-16000113

Keywords: Trust; Data Validity

\section{Letter to Editor}

Recently Baron RJ, et al. [1] addressed a fundamental problem underlying the physician-patient relationship --Trust. While that trust has not completely eroded away, it is clear that we have our work cut out for us [2,3]. Much of the erosion is a direct result of the influence the pharmaceutical and food industry has had upon physicians and researchers [4]. To restore that trust it is important that we demonstrate a willingness to transparently discuss our data and prove its validity [5]. Only by doing so, will we be able to openly and honestly discuss research and treatment options with our patients and restore the trust, which is the foundation of the patient-physician relationship.

\section{References}

1. Baron RJ, Berinsky AJ (2019) Mistrust in Science - A Threat to the Patient-Physician Relationship. NEJM 381(2): 182-185.
2. Funk C, Hefferon M, Kennedy B, Johnson C (2019) Trust and Mistrust in Americans' Views of Scientific Experts. Pew Research Center Science \& Society.

3. George SL, Buyse M (2015) Data fraud in clinical trials. Clin Investig 5(2): 161-173.

4. Keller F, Marczewski K, Pavlovic D (2016) The relationship between the physician and pharmaceutical industry: background ethics and regulatory proposals. Croat Med J 57(4): 398-401.

5. Fleming RM, Fleming MR, Chaudhuri TK (2019) Establishing Data Validity: Statistically determining if Data is Fabricated, Falsified or Plagiarized. Acta Scientific Med Sci 3(8): 169-191. 